\title{
PRACTITIONERS' PERCEPTIONS OF THE GAP BETWEEN THE RHETORIC OF MOSER COMMITTEE SFL RECOMMENDATIONS AND THE REALITY OF POLICY IMPLEMENTATION
}

\author{
Gordon O. Ade-Ojo ${ }^{\mathrm{a} *}$ \\ ${ }^{a}$ University of Greenwich, School of Education, UK, G.O.Ade-Ojo@greenwich.ac.uk
}

\begin{abstract}
This paper reports the findings of a study which sought to explore the gap between the rhetoric of the Skills for Life (SfL) policy and the reality of implementation from the view point of practitioners. The study assumes the position that an analysis of policy implementation is most fruitful if it took into account varying views as advocated by the post-modernist/behavioural paradigm of implementation gap analysis. Data were collected through the use of a questionnaire supported by a focus group interview from a convenience group of trainee specialist SfL teachers. The study found that practitioners predominantly held the view that there were gaps between the SfL policy elements and the reality of their implementation. It concluded that among several possible reasons for the observed gap, the absence of meaning makers between policy makers and policy implementation might be one of the most significant. The study, therefore, advocated for policy makers to endeavour to include meaning makers in the process of policy making.
\end{abstract}

Keywords: Policy, implementation, gap, SFL, meaning makers, structural, behaviourist and political paradigms

(C) 2012 Published by C-crcs. Peer-review under responsibility of Editor(s) or Guest Editor(s) of the EJSBS.

${ }^{*}$ Corresponding author.

E-mail address: G.O.Ade-Ojo@greenwich.ac.uk

doi: 10.15405/FutureAcademy/ejsbs(2301-2218).2012.1.5

This work is licensed under a Creative Commons Attribution-NonCommercial-NoDerivatives 4.0 International License. 
https://doi.org/10.15405/FutureAcademy/ejsbs(2301-2218).2012.1.5

eISSN: 2301-2218 / Corresponding Author: Gordon O. Ade-Ojo

Selection \& Peer-review under responsibility of the Editors

\section{Background}

Numerous studies have attempted a comparison between policy intentions, their attendant claims and the reality of implementation in a range of settings. Almost without fail, these studies have all identified a gap between what might be called the rhetoric of policy and the reality of implementation (Ade-Ojo, 2011; Results, 2010; Steinbach, 2009; Bossuyt/ECDPM, 2008; Yates and Payne, 2007, Callejo, 2006; Kelly, 1997). One other constant with these studies is the fact that most of them have drawn from a positivist causeand -effect paradigm (Gilg \& Kelly, 1997) which often tended to simply analyse structural and statistical evidence in their measurement of gap between policy and implementation (See e.g. NAO, 2004). This ignores the strength of approaches like the behaviourist/postmodernist paradigm (Gilg \& Kelly, 1997) or the related ecological paradigm (Cousin, Deepwell, Land, \& Ponti, 2004) and, therefore, takes very limited cognisance of the views, or more importantly, the perception of practitioners on the extent to which the promise of policy intention is matched by the reality of practice. This, in spite of the fact that many of these studies (Callejo, 2006, Steinbach, 2009) acknowledge the role of practitioners, who Callejo (2006) refer to as 'streetlevel bureaucrats' in the implementation of policy, and the claim that, 'if we are to know how policy models work, we must research policy in practice' ( $\mathrm{p} 1)$. In the context of this work, I adopt the term 'street level bureaucrats' to include in particular teachers, who are at the 'chalk face' of SfL policy delivery. In my view, it is difficult, if not impossible, to fruitfully research policy in practice without taking into account the views of such 'street level bureaucrats' who should be seen as 'social agents who interpret policy goals and use a considerable amount of discretion in the practice of their duties' (Callejo, 2006, p1). This, ultimately, is the limitation of the positivist evaluation model of comparing policy with practice which seems to have permeated reviews of social and educational policy. Moving away from the seemingly entrenched evaluative model is one justification for the present work, as it intends to explore 
https://doi.org/10.15405/FutureAcademy/ejsbs(2301-2218).2012.1.5

eISSN: 2301-2218 / Corresponding Author: Gordon O. Ade-Ojo

Selection \& Peer-review under responsibility of the Editors

the gap between SfL policy and its implementation from a perspective of those involved at a much lower level of policy through the lenses of post-modernism.

The second justification for this work is rooted in the context on which it is focuses. Since the recommendations of the Moser Committee (1999), the attendant SfL policy that it generated has been the driver for the provision of Skills for Life in England and Wales. In the current climate however, there is some evidence that the SfL agenda is nearing its end and that it will soon be replaced by either some other variants or by a totally new agenda. On the basis of this, it becomes crucial that the extent to which the policy is perceived to have been delivered is explored. The ultimate goal of this is that it will add to our understanding of how and why the vision of policy makers might take drastic departures from the reality of practice and the impact of such departures on practitioners.

Existing studies have commented on the gap/affinity between SFL policy and practice from the practitioners' view (see e.g. Coffield, Edward, Finlay, Hodgson, Spours, Steer and Gregson, 2007). However, the account given in many of these studies appear to be reductionist in nature as they have not, in my view, significantly factored in the particular views of actual practitioners who are in the position to highlight the discrepancies between policy and what obtains in the reality of practice. For example, Coffield et al. (2007) reported 'positive comments from long-term basic skills serving managers' in their study on the impact of policy on learning setting (p.10). Such views are bound to be significantly different from those of actual tutors whose experience and perception of policy and practice is bound to be different.

The goal of this study, therefore, is two-fold. First, to we move away from the fatalistic acceptance of the disparity between policy and practice as inevitability to a constructive exploration of the reasons, if studies such as this are to be of any value to policy makers and second, to capture the views of actual practitioners which is not adequately represented in some of the existing exploration of the link between policy and practice. 
https://doi.org/10.15405/FutureAcademy/ejsbs(2301-2218).2012.1.5

eISSN: 2301-2218 / Corresponding Author: Gordon O. Ade-Ojo

Selection \& Peer-review under responsibility of the Editors

\subsection{The Moser Committee and the national Skills for Life policy}

Perhaps the most significant policy in the Life-long Sector over the last two decades is the Skills for Life agenda. Serving as a precursor to this agenda is the recommendations of the Moser Committee, which led to the publication of the policy document, A Fresh Start (1999) that contains a number of distinct elements. These elements are relevant for this research to varying degrees, as they constitute what is described as the national strategy for adult basic skills (p.10). These elements are: national targets, entitlement to learn, guidance, assessment and publicity, better opportunities for learning, a new curriculum, quality, a new system of qualifications, teacher-training and inspection, planning of delivery, the benefits of new technology and funding. The discussion of the responses from the practitioners is located in the context of eight of these elements. The choice of these eight elements is informed by the direct relationship they have to practitioners' role in the implementation of policy. While the other elements have their relevance, it is my view that they do not directly relate to practitioners in the context of their practice as much as the eight selected elements.

Finally, it is important to highlight here why this study has opted to use the Moser report as the source for policy initiatives. In my view, although many policy initiatives have been generated by the government since Moser, there is no doubt that most of them have drawn from the recommendations of the Moser committee. As such, using the Moser committee as a reference point offers a more structured approach to the analysis of policy.

\subsection{Theorising the gap between policy and implementation}

Taking sides in the debate on the suitability of paradigms of policy and implementation gap analysis is not a central concern of this paper. Nevertheless, it is important to look at some of the models offered in the literature in order to identify elements of such analysis from which this study can draw. In essence, therefore, the goal here is not to postulate theoretical 
https://doi.org/10.15405/FutureAcademy/ejsbs(2301-2218).2012.1.5

eISSN: 2301-2218 / Corresponding Author: Gordon O. Ade-Ojo

Selection \& Peer-review under responsibility of the Editors

supremacy. Rather, it is to draw on features of existing paradigms to offer explanations on some of the features presented in this study.

Numerous studies on the gap between policy and implementation have often assumed a micro dimension. This approach individualises elements of observed gaps and hypothesise on the possible reasons for their existence. Such studies can be classified into two with one attempting to account for gaps with the approach to implementation (See e.g., Steinbach, 2009, Gilg \& Kelly, 1996a, Gatenby \& Williams, 1996) and the other accounting for the gap with the nature of the policies (see e.g. Yates and Payne, 2007). A logical implication of the micro level nature of this approach is that it is likely to limit the significance of gap analysis to individual policies.

Other studies have taken a more macro approach to gap analysis. Typifying this approach is the study by Gilg and Kelly (1997) who, in addition to identifying reasons for specific gaps between policy and implementation in an earlier study (1996a), also offer theoretical and methodological approaches to explaining and assessing the implementation gap (1997). According to them, the available paradigms for analysing implementation gap are the 'logical positivism and statistical analyses; political economy and structural analyses, and the behavioural/humanist and post-modern approaches' (p. 19).

The first of these paradigms draws from the assumption that there is a 'straightforward cause-and- effect link between policy and its implementation' (p. 19). There is abundant criticism of this approach with one of the main ones being that in reality, the connection between cause and effect is very blurred and the fact that this approach can only show broad trends while ignoring the dynamics between stakeholders in the decision making process (Cloke 1987; Pearce 1992).

The second approach, political economy and structural analysis, is founded on the assumption that the implementation gap is explained by the 'differential access to power held by different groups in society' (Gilg \& Kelly 1997, p. 20,). A major strength of this approach 
https://doi.org/10.15405/FutureAcademy/ejsbs(2301-2218).2012.1.5

eISSN: 2301-2218 / Corresponding Author: Gordon O. Ade-Ojo

Selection \& Peer-review under responsibility of the Editors

is the conceptual view it holds of how power is structured thereby improving our understanding of 'development-control' decision making (Gilg \& Kelly 1997, p. 20). In spite of this strength, the approach falters on the ground that it seems to focus predominantly on the human agency to the exclusion of structural factors thus presenting a uni-dimensional view.

The third approach draws from the position that 'human beings are neither the rational beings implicitly assumed in logical positivism nor the prisoners of economic processes or their class as propounded by the political economy school' (Gilg \& Kelly, 1997, p. 21). Rather, it assumes that human beings have a measure of freedom and are usually substantially influenced by the views and values they hold (Tewdr-Jones, 1995). The present study could benefit from this position through the recognition of the fact that a study of any implementation gap must necessarily entail the dynamics that operates between a variety of stakeholders who hold conflicting views and values. In a sense, the quintessence of implementation gap might well be a reflection of the divergence in values and views amongst the various participants and stakeholders. This echoes the invocation of the metaphor of ecology (Cousin, Deepwell, Land, \& Ponti, 2004) which sees implementation as non linear and complex, as it has a range of implications for different stakeholders. It also echoes Alverson's (2002) notion of 'multiple dynamic' configurations which suggests that implementation is not just a series of steps but a framework which requires the interrogation of relationships. More importantly, the paradigm offered by Gilg and Kelly's post-modernism (1997) and its variants like Alverson's multiple dynamics (2002) and Cousin, Deepwell, Land and Ponti's, (2004) framework of ecology provide a flexible framework for acknowledging divergent views and an opportunity to accommodate them.

In the context of this study, the identification of practitioners' views is a direct reflection of the recognition of diverse views and perceptions. On the one hand, it admits the views of practitioners as a distinct variable while on the other, it allows for difference of views 
https://doi.org/10.15405/FutureAcademy/ejsbs(2301-2218).2012.1.5

eISSN: 2301-2218 / Corresponding Author: Gordon O. Ade-Ojo

Selection \& Peer-review under responsibility of the Editors

and values among members of the same group. These are elements of the post-modernist position that are considered as useful for the analysis that is intended in this study.

\section{Methods of Data Collection and Analysis}

\subsection{Selection of sample group}

The sample group in this study is a convenience sample (Bernard \& Ryan 2010; Thomas 2009) which was drawn from a group of specialist Skills for Life (SfL) teachers who have undertaken a specialist programme taught by this researcher over a period of five years. It is considered convenient because it offers easy access to a readily available group. However, limited representation of the convenience group was tempered by the introduction of stratification (Bernard \& Ryan, 2010; Thomas 2009). First, the spread of the group is representative of the location of colleges and other providers of SfL in the region within which the research and researcher are based. Second, there was a full representation of the types of providers, ranging from formal FE colleges through providers in the services like The Police and Prison services, to private trainers and voluntary organisations. Therefore, views from the possible range of provider types were represented in the data. There was a reasonable balance between male $(42 \%)$ and female $(58 \%)$ practitioners. This reflects the established pattern within the workforce in the subject area (Cara et al. 2008, Hamilton and Hillier 2006, Fowler 2005). Finally, the sample included representatives of practitioners in the three SFL subject areas, ESOL (38\%\%), literacy (42\%) and numeracy (20\%). While the disparity in numbers between ESOL and Literacy on the one hand and numeracy on the other hand might appear to be a source of concern, it is essentially a reflection of the overall number of practitioners in the field and their representation on training programmes at the university. Overall, therefore, there was sufficient stratification within the group to provide a reasonable level of representativeness. 
https://doi.org/10.15405/FutureAcademy/ejsbs(2301-2218).2012.1.5

eISSN: 2301-2218 / Corresponding Author: Gordon O. Ade-Ojo

Selection \& Peer-review under responsibility of the Editors

\subsection{Methods of data collection}

The first level of data was collected through the use of a questionnaire. In the questionnaire, questions were designed around eight elements of the defining document for the SfL policy, The Moser Report (1999) which practitioners have the opportunity to assess in the context of their day to day engagement at work. Also, opportunity was provided for respondents to input their interpretation of policy elements. This enabled the researcher to map out expectations against reality in the perceptions of respondents.

While the established advantage of using a questionnaire in order to achieve more responses was instrumental to its use in this study, the problems associated with its use such as low survey return rates, problems with memory and rigidity of questions (Wilson, 2009) were all considered and addressed. Low response rate was addressed through the fact that the study focused on a convenience sample which provided a more than average response rate of 76 out of $125(61 \%)$ considered to be representative of the range of possible opinions.

The questions in the questionnaire had two foci. The first was to establish participants' perception of the intention of policy. That is, participants were requested to provide their understanding of the goals of policy statements around each of the eight elements. The second goal was to find out the extent to which the actual implementation of these elements of policy matched their perception of its inherent promise. Based on their response to these, a view was taken on the extent to which they felt that the realities of practice matched the rhetoric of policy.

The second level of data was collected through the use of a focus group interview and used for triangulation and clarification. Specific respondents were identified and interviewed in a focus group setting. Although a focus group interview is often considered limited because of the 'unnaturalness of the setting' (Cohen et al., 2000, p. 288), this problem was surmounted through the provision of clear thematic boundaries which yielded significant information. More importantly, the interaction was effectively among the participants rather than with the 
https://doi.org/10.15405/FutureAcademy/ejsbs(2301-2218).2012.1.5

eISSN: 2301-2218 / Corresponding Author: Gordon O. Ade-Ojo

Selection \& Peer-review under responsibility of the Editors

interviewer, leaving room for the views of the participants to emerge. As noted by Chen et al. (2000, p.288), 'it is from the interaction of the group that the data emerge'.

\subsection{Methods of data analysis}

The method of data analysis in this study was essentially content analysis (Thomas, 2009). The focus of content analysis in this study was to define language use which would identify boundaries of social relations and in particular, power relations. In order to achieve this goal, the data collected through the questionnaire and those collected from the transcription of the focus group interview were first codified using the connotations of negativity, positivity and a range of medial terms in the context of trust in relationships. Following this, the data was then analysed in order to establish a simple statistical pattern based on negative and positive dispositions towards trust in the context of each policy element. The data is then presented through a combination of statistical and textual media.

\section{Findings and Discussion}

\subsection{Entitlement to Learn}

'Every citizen with worries about literacy or numeracy should have a clear entitlement to a choice of opportunities for learning, and indeed access to a wide variety of study programmes'

Responses from participants in the context of this policy element were varied. This highlights the post-modernist expectations of accounting for gaps between policy and implementation to reflect varying views and values (Gilg \& Kelly, 1997). A small number of participants $(3.9 \%)$ were of the view that the policy element had in practice fully met their expectations. This group of participants focused on the proliferation of providers of literacy tuition around the country: 
https://doi.org/10.15405/FutureAcademy/ejsbs(2301-2218).2012.1.5

eISSN: 2301-2218 / Corresponding Author: Gordon O. Ade-Ojo

Selection \& Peer-review under responsibility of the Editors

'At no time have we had so many colleges and providers offering people places to study literacy. I think anyone who wants a literacy class can always get one' (Participant 24).

The key question in this context is the type of places on offer and the nature of the provision available. This appears to be central to the argument of the majority of participants (76.3\%) who felt that the policy had only met their expectations to a limited extent as illustrated by participant (18):

'If we believed that offering the Core Curriculum driven programmes will solve the literacy and numeracy worries of everyone in the country, we really have a limited understanding of people's needs'.

Furthermore, the element of funding and the drive towards profitability were seen as blocks debarring the implementation of this policy element from meeting the expectations of participants:

'Only those who are on benefits can generally take on any of these courses freely. Many of those who have specific literacy needs are unable to benefit because of the cost. After all, we are corporations now and must guarantee our profit levels in order to survive.(Participant 6).

For participants who saw the policy element as having met their expectations to a large extent (19.7\%), the combination of available places and the introduction of non traditional forms of delivering literacy were crucial factors: 
https://doi.org/10.15405/FutureAcademy/ejsbs(2301-2218).2012.1.5

eISSN: 2301-2218 / Corresponding Author: Gordon O. Ade-Ojo

Selection \& Peer-review under responsibility of the Editors

'Although the opportunities might not be as creative and diverse as the people's needs are, the fact is that they have been made available and developments like embedded and integrated studies are beginning to add a lot more innovation and creativity to the programmes on offer' participant (54).

The findings above suggest that practitioners' perceptions vary significantly. While it is clear that the majority of practitioners highlight a gap between policy and practice, it would seem that individual views and values might be responsible for the variance noticed. For example, the contrast between the realities observed by some practitioners that opportunities are still largely informed by funding potential and those who perceived abundance of opportunities might be accounted for by a difference in views and values.

\section{Better Opportunities for Learning}

'Research suggests that more intensive programmes increase the success rate of basic skills learners, and that longer periods of study are necessary for those with the weakest skills. We must ensure that such opportunities are widely available. There should be a wide diversity of places and programmes in which people can access learning. All forms of provision need to be expanded, especially those that can reach adults at present felt - however wrongly - to be out of reach'

Questionnaire response and contributions during the focus group sessions suggest that the expectations of participants were that this policy element will provide significant opportunities for learners to study at different times and a general movement away from the one size fits all model. However, participants' views are varied. More than half (51.3\%) felt that their expectations had been met only to a limited extent. Issues of lack of flexibility in the curricula on offer, rigidity in the timing of provision, the assessment driven nature of many curricula and the unchallenging nature of many of the curricula on offer were highlighted. Typifying this view are comments such as: 
https://doi.org/10.15405/FutureAcademy/ejsbs(2301-2218).2012.1.5

eISSN: 2301-2218 / Corresponding Author: Gordon O. Ade-Ojo

Selection \& Peer-review under responsibility of the Editors

'Opportunities are open mostly to those who can attend college at a specific time. 'We have very limited options in terms of time learners are expected to attend lectures. Some of my students had to drop out because we did not have the option for them to have weekly intensive programmes which will allow them to continue to carry out their work and family responsibilities' (Participant 46),

Most curriculums are similar with all of them targeted at the range of qualifications offered by many awarding bodies and which are of little interest to many learners' (participant 62),

And,

'There are only very few programmes that have sufficient flexibility to cater for many work and personal needs of potential learners' (Participant 73)

Contrary views represented were anchored on the arguments that many providers now offer programmes on full time basis and that the advent of ICT has provided additional opportunities. The thorny point is the perception of the nature of curricula, and the flexibility of the timetable on offer. Though many providers now offer larger programmes including twilight sessions, the extent to which these attributes meet the highly varied individual circumstances of potential learners is still contested. A small minority $(2.6 \%)$ felt that their expectations had not been met at all. The arguments of this minority were less explicit and generalised condemnatory comments like 'It is all a game' (participant

3) and 'What kind of opportunity offers you a chance to gain an E3 qualification by multiple choice tests' (Participant 38) were indicative of the casualness of their dismissal. 
https://doi.org/10.15405/FutureAcademy/ejsbs(2301-2218).2012.1.5

eISSN: 2301-2218 / Corresponding Author: Gordon O. Ade-Ojo

Selection \& Peer-review under responsibility of the Editors

\subsection{A New System of Qualifications}

'It is also vital that we have qualifications which are credible indicators of a person's literacy and numeracy. Unless the qualifications are credible, they cannot do the job that is needed. The key criterion in planning for a new system of qualifications is that they should be attractive to potential learners, and positively useful to them in their work, in seeking and getting jobs, and in moving on to further learning. The new system of qualifications we propose will be based on the new curriculum and on uniform standards of skill. It will be available at a number of levels, and it can be taken in 'bite-size' chunks. Ready access for the learner is crucial. Coursework assessed'

Participants' expectations of this element of policy can be summarised as follows; The provision of qualifications that are recognised and accepted by employers, higher and further institutions and valued by learners themselves; a differentiated set of assessments and an assessment system that will be flexible enough to address the varied range of needs represented by learners.

The majority of participants $(67.1 \%)$ held the view that this element of policy has met their expectations only to a limited extent. Yet, many of them acknowledged some positivity in the implementation of this policy element; Qualifications are now attached to the programmes, awards have improved the self esteem of many of their learners. Participant (8) said 'many of my learners now know they will get something at the end of their study and they do look forward anxiously to receiving their certificates'. Participant (49) pursuing a similar theme claimed: 'These certificates do a lot for the self esteem of my learners even if some people think they are not worth anything. My students really cherish them'.

However, the dissenting voices, including those who felt that the policy element had met their expectations to a large extent, raise a legitimate concern about the value of the certificates. Many claim that the certificates are essentially worthless as 'The certificates will not fetch you a job on their own merit' (Participant 67) and, 'Even our own college will not 
https://doi.org/10.15405/FutureAcademy/ejsbs(2301-2218).2012.1.5

eISSN: 2301-2218 / Corresponding Author: Gordon O. Ade-Ojo

Selection \& Peer-review under responsibility of the Editors

allow our students to progress to higher level courses with these certificates' (Participant 57).

The position of the $23.6 \%$ of participants who felt that this expectation had been met only to a limited extent, and the $1.3 \%$ who felt their expectations had not been met at all can be understood in this context. Instructive in this sense is the comment of the lone voice who felt that their expectations had not been met at all: 'what use is a qualification that cannot get you a job or into training? In fact, the qualifications cannot help our learners to meet their original personal goals' (Participant 73).

In essence, while it is beyond debate that the majority of participants recognise the emergence of specific qualifications and in some cases the socio-psychological values of these certificates, the academic and pragmatic values of these certificates are still seen as questionable.

\subsection{Teacher Training and Inspection}

'At present, too many teachers teach part-time, and some are inadequately prepared. To achieve our aims, many more teachers will need to be trained to teach for the new curriculum. We shall require over 15,000 full-time equivalent teachers in this area, compared with under 4,000 at present'.

The common interpretations given to this element of policy include the expectations that; there will be sponsored opportunities for teachers to gain qualifications including allocation of quality time to study and attend classes and that there will be many more fulltime tutors recruited thus signalling an end to the era of part-time tutors

A total of $67 \%$ of participants felt that this element of policy has either fully or mostly met their expectations. At the core of this position is the range of external and internal training programmes that have been made available and to which many practitioners have been sponsored. Similarly, participants identified the fact that recruitment and staffing levels have improved significantly since the introduction of this policy element: 'staff have 
https://doi.org/10.15405/FutureAcademy/ejsbs(2301-2218).2012.1.5

eISSN: 2301-2218 / Corresponding Author: Gordon O. Ade-Ojo

Selection \& Peer-review under responsibility of the Editors

benefitted from many training programmes and they have helped to improve our skills'

(Participant 6). Another participant saw this from the viewpoint of improved professionalism:

'Lecturers now feel like they are professional since gaining their specialist awards'

(Participant 28). A final illustration of this position is encapsulated in participant 70's comment that, 'Literally, staff strength has more than doubled since I joined my college' (Participant 39). All these give the indication that this element of policy has made significant advances in terms of meeting the expectations of practitioners.

However, some participants were less positive. They identified failure to fund courses and the continuous presence of part-time lectures as evidence of the failure to meet expectations: 'My college still recruit on the cheap and will take on agency staff instead of creating full time posts to meet obvious needs' (participant 33). Supporting the argument that funding might still be difficult to secure, participant 76 claimed, Some colleagues get funded, but only to courses the managers decide. Many of us are still turned down when we apply to be funded on useful courses' (Participant 75). It would seem that there is an element of local coloration at play in this context and that the differences amongst colleges are manifested in the variation in responses from the participants. This again highlights the significance of different values and views.

\subsection{Our priority Groups}

'Those who are improving their literacy and numeracy skills whilst studying other subjects will no longer have to do so within the current 16-hour rule. Unemployed people will be encouraged and helped to continue with their learning after they return to work. All literacy and numeracy skills provision will be free to them and quality assured'.

Participants' understanding of this element of policy was to the effect that anyone willing to improve their skills should be given the opportunity without prejudice to the level of study. In response to this policy element, there appears to be a relatively even distribution 
https://doi.org/10.15405/FutureAcademy/ejsbs(2301-2218).2012.1.5

eISSN: 2301-2218 / Corresponding Author: Gordon O. Ade-Ojo

Selection \& Peer-review under responsibility of the Editors

with $47.3 \%$ and $42.1 \%$ agreeing that the policy element had met their expectations to a large and a limited extent respectively. For the latter, the focus of the delivery of this element of policy has remained on regular learners who meet a particular set of conditions. These include being able to go to the venue of provision at specific times, the predominance of young learners who are most likely to help the providers meet other policy conditions like assessment and achievement, the standardised nature of the provision, and the fact that it is almost impossible to combine other studies with SfL studies in some colleges. Participant (31) commented that,

It is virtually impossible for learners to be able to combine their studies with other vocational choices in many cases. This is possible for young learners but with adult learners, the cost and the rigidity of the timetable hardly permit this to happen.

For those who felt that the policy element had largely met their expectations, there were references to the link between government agencies like the Jobcentre which consistently send jobseekers to colleges to undertake SfL studies: 'Through the Jobcentres, all unemployed people have a chance t study SfL in our college'(Participant 66). A crucial question in this regard though is whether these learners were really interested in SfL studies in the first place. Another line of argument for those who felt that the policy had met their expectations only to a limited extent revolves around the issue of enabling support. While the offer is available and accessible, there is no provision for addressing other enabling needs of the learners:

It is true that places are available for most learners, but little provision is made for addressing other needs of the learners which will enable them to take up these places; transport, welfare, housing etc (participant 25). 
https://doi.org/10.15405/FutureAcademy/ejsbs(2301-2218).2012.1.5

eISSN: 2301-2218 / Corresponding Author: Gordon O. Ade-Ojo

Selection \& Peer-review under responsibility of the Editors

\subsection{A Learner Focus}

'Providers will be regularly inspected to ensure that all learners: have an action plan which includes short- and long-term goals; receive regular positive feedback; have access to a full range of learning techniques; are supported by volunteers; and receive guidance on progression to other learning opportunities at higher levels'

Participants' expectation of this policy element included a proper regulatory system that will focus on learning; a departure from the bureaucratic process of inspections which follow paper trails; and the opportunity to focus on the actual needs of learners rather than needs imposed on them. The majority of participants (59\%) agreed that this policy element has either fully met or met their expectations to a large extent with many citing the fact that learning plans for learners is now central to most provisions: 'All our learners have ILPS which we monitor consistently in order to measure their progress and to help them progress in their learning' (Participant 30). Also, the introduction and use of initial and diagnostic assessment tools was highlighted:

The introduction and use of diagnostic and initial assessment tools has ensured that we properly place our learners and establish their learning needs even before their learning commences (participant 44).

However, the $25 \%$ of participants who felt that this element of policy had only met their expectations to a limited extent cite the bureaucratic nature of the use of ILPS and the disproportionate time teachers are compelled to spend on administering these ILPS as indications of the failure of policy to meet expectations: 
https://doi.org/10.15405/FutureAcademy/ejsbs(2301-2218).2012.1.5

eISSN: 2301-2218 / Corresponding Author: Gordon O. Ade-Ojo

Selection \& Peer-review under responsibility of the Editors

Though we use ILPS, it is more an exercise in file keeping than an instrument for real learning' (Participant 55), 'Yes we use ILPS, but the time devoted to it leaves little room to prepare creative lessons and resources (Participant 68).

In spite of the slant towards a perception of the policy element meeting expectations significantly, the number of participants who felt that their expectations had been met only to a limited extent suggests a significant gap between expectations and reality.

Guidance, Assessment and Publicity:

'Individuals with basic skills problems should be entitled to free confidential assessment, whether they are employed or unemployed

'High quality guidance and information on basic skills courses need to be freely available to all potential learners. Furthermore, to ensure that learners get on to appropriate courses, it is essential that, however they arrive there, they have had an assessment recording the skills with which they enter the programme'

Participants' had three main expectations of this policy element. These are that, there will be some flexibility to leverage resources to accommodate request, opportunity will be available at all times for learners to engage with study programmes and that there will be a well designed set of initial assessment tools that will allow variation in assessment $65 \%$ saw the implementation as having met their expectations only to a limited extent with the issues of information available being tailored to what providers have and the fact that the initial assessments tools are actually tailored towards an already determined end presented as key:

Information is provided regularly but only about what we already have on offer. The fact is that we cannot provide any other form of information because we are not flexible enough to respond to specific needs. They have to take what we offer or nothing (Participant 19). 
https://doi.org/10.15405/FutureAcademy/ejsbs(2301-2218).2012.1.5

eISSN: 2301-2218 / Corresponding Author: Gordon O. Ade-Ojo

Selection \& Peer-review under responsibility of the Editors

In respect of the point raised about initial assessment tools,

Our initial assessment activities are geared towards placing learners on mainstream courses that we already have in existence. We are not equipped to use the outcomes of initial assessment to respond to specific needs of our learners (Participant 49).

In spite of the strong feelings expressed by the views above, a total of $34.2 \%$ of participants felt that this policy element had fully met, or met to a large extent, their expectations with a focus on the frequency of assessment and guidance days and the ready literature available to potential learners:

As with other most providers, we hold $A \& G$ days at least once a week throughout the year and applicants are provided with detailed information about available courses (Participant 60).

We always have a ready stock of brochures and other literature which provide information and which applicants can have on demand (Participant 2).

It appears that the point of contention is on the quality of what is provided during the assessment and guidance events. How well does it meet the actual needs of the potential learners? The debate around the quality of what is provided can legitimately be seen as driven by the differences in views and values held by the proponents of each side of the debate.

\subsection{Quality}

'But we need not only enough provision, but provision of such good quality that it will lift peoples' competence in a clear and demonstrable way, and be a positive attraction for 
https://doi.org/10.15405/FutureAcademy/ejsbs(2301-2218).2012.1.5

eISSN: 2301-2218 / Corresponding Author: Gordon O. Ade-Ojo

Selection \& Peer-review under responsibility of the Editors

students. Four elements are essential for ensuring high quality: · clear, unambiguous national quality standards; a well- defined curriculum; · a credible set of qualifications; $\cdot$ a new system of teacher training and inspection'

A summary of participants' expectations include the recognition that quality also involves learners' views rather than just management and regulatory body's views and the evolution of qualifications that can get learners to progress to employments and higher level studies

A fairly even spread was recorded although participants who felt that the policy had only met expectations to a limited extent $(55.2 \%)$ were in the majority. While most of these participants had no issues with the establishment of a range of tools for maintaining standards, they questioned the adequacy of these tools. They saw the inspectorate regime as not concerned with maintaining standards but 'a bureaucratic tool for ticking boxes which lacks flexibility and has become a tool for managers to bully staff' (participant 20). Similarly, they challenged the credibility of the qualification system which some see as ' .... a worthless set of papers that neither offer learners access to work nor placement in further studies'. The $44.7 \%$ of participants who felt that the policy had fully or mostly met their expectations emphasised the role of inspection as,

a tool for getting many lazy teachers to do their jobs properly, and allowing managers to control these lazy teachers and a vehicle for recognising good work by hard working teachers (Participant 50).

The varied response suggests that there are gaps between expectations and the reality which is seen through different lenses and reinforces the view that views and values should be seen as crucial to any analysis of implementation gap.

From the responses and views of participants above, it is clear that there is a clear divergence between practitioners' expectations of policy and the reality of implementation on 
https://doi.org/10.15405/FutureAcademy/ejsbs(2301-2218).2012.1.5

eISSN: 2301-2218 / Corresponding Author: Gordon O. Ade-Ojo

Selection \& Peer-review under responsibility of the Editors

the one hand and amongst participants on the other. In my view, this can be accounted for by the notion of divergence of values. This can be explored from two perspectives. In the first place, it is useful to draw on the framework of perceptions of LLN (See e.g Fowler, 2005; Hamilton \& Hillier, 2007) which identifies a social as against a cognitive perception of LLN. For participants who accepted that the elements of policy have met the reality of implementation, it is plausible to argue that they share the same value position as the policy makers in terms of their perception of what constitutes literacy LLN and the ways in which it is best structured and delivered. As reported in the literature, the perception that is often attributed to the government and policy makers is the autonomous model (Street. 1983 and 1995) which holds a view of LLN as something cognitive and therefore accommodating of the one- size-fits all model that is often reflected in policy (See Ade-Ojo 2011, Hamilton and Hillier 2007, and Fowler, 2005). By contrast, it could be argued that the driving value for those who hold the opposite view is likely to be a social model of literacy which sees LLN as social practice and therefore advocates for its provision to meet the social needs and reality of learners. Essentially, therefore, the conflicting values here appear to be based on perceptions of LLN.

The second source of conflicting value may be attributed to the underpinning values of that drove the recommendations of the Moser committee. As reported in Ade-Ojo $(2011,2009)$ and Fowler, (2005), there is strong evidence that the recommendations of the committee were more informed by economic rather than emancipator and educational values. There is a strong sense from the focus group discussions that many of the participants were more driven by the latter rather than the former value position. It is, therefore, logical that there will be conflicting perceptions of what constitutes reality and on expectations between practitioners and policy makers and indeed amongst practitioners who naturally may hold divergent value positions. 
https://doi.org/10.15405/FutureAcademy/ejsbs(2301-2218).2012.1.5

eISSN: 2301-2218 / Corresponding Author: Gordon O. Ade-Ojo

Selection \& Peer-review under responsibility of the Editors

\section{Conclusions}

The central focus of this study was to establish the extent to which practitioners' perceptions of policy intentions converge with their perceptions of the reality of implementation. As suggested in several studies, it is almost an expectation to 'observe a gap between what was planned and what actually occurred' (Steinbach, 2009, Buse et al., 2005). This study confirms this viewpoint as it shows that there are varying perceptions of divergence between policy and implementation.

While this finding appears to be straightforward, such a conclusion on its own adds little value to policy making processes. In order to offer a macro-level use for the findings of this study, I start by drawing from the post-modernist framework for analysing implementation offered by Gilg and Kelly (1997). This framework highlights the significance of divergent values and views between policy makers and practitioners and amongst members of the same group like practitioners in this study. It seems that the perceived gaps are better explained in the context of the differences in views and values between practitioners and policy makers. This assumes a high level of significance from the viewpoint that it is essential that both practitioners and policy makers be involved in policy formation and implementation as neither of them is dispensable if policy is to achieve its goals. In the case of SfL policy, it would seem that this type of collaboration was limited as previous studies indicated that there was little or no involvement of practitioners in the policy formation process (See e.g. Ade-Ojo, 2011). This suggestion does not, however, ignore the problems of such a bottom - up approach including the tendency to eliminate a much desired bureaucratic accountability and the attendant difficulty of being able to evaluate the effects of policy (Steinbach, 2009).

A second view developing from this finding is to take what might be considered a micro-level approach by simply offering potential reasons for the gaps noticed. Three major theoretical approaches have been offered for exploring policy implementation at this level (Buse et. al., 2005; Steinbach, 2009). The first, a top-down approach, totally separates policy 
https://doi.org/10.15405/FutureAcademy/ejsbs(2301-2218).2012.1.5

eISSN: 2301-2218 / Corresponding Author: Gordon O. Ade-Ojo

Selection \& Peer-review under responsibility of the Editors

formation from policy implementation. With a desired goal of epidemiological expectation of association and causation, it only adopts the perspective of policy makers and ignores the views of other stakeholders. The second, the bottom up approach, gives more credence to the involvement of individuals and groups at the subordinate levels. The third, principal-agent theory, advocates a stage by stage interaction between policy makers and implementation agents. In offering a micro-level explanation of the gap between policy and implementation, there is an option accounting for the gap with the claim that the use of one of the above approaches might be responsible.

Moving away from a theoretical engagement, there is no doubt that from the perception of practitioners, there is a gap between policy and implementation. In my view, this is not necessarily adversarial. What is important is for all stakeholders to use a barometer such as this to explore the extent to which policy implementation meets the perceptions of all stakeholders. It is in a drive towards achieving this that we might make a recourse to the injunction of (Cousin, Deepwell, Land, \& Ponti, 2004) that given the ecological structure of policy planning and its implementation, the drive towards convergence requires 'meaningmakers or mediators between the different elements of the ecology who are able to interpret what is happening and consider creating linkages between them when they are not emerging organically' (p7). It would seem that the emergent pattern in terms of the gap between SfL policy and implementation is the aftermath of the absence of 'meaning-makers' between policy makers and implementation agents. Ensuring that such mediators are put in place is the challenge for policy makers.

\section{Acknowledgements}

The authors declare that there is no conflict of interest. 
https://doi.org/10.15405/FutureAcademy/ejsbs(2301-2218).2012.1.5

eISSN: 2301-2218 / Corresponding Author: Gordon O. Ade-Ojo

Selection \& Peer-review under responsibility of the Editors

\section{References}

Ade-Ojo, G. O. (2011). Practitioners' perception of the impact of the vision of policy makers on practice: the example of the recommendations of the Moser Commission. Research Papers in Education 200, 26(1), 53-74.

Alverson, M. (2002). Understanding Organisational Culture, London, UK: Sage Publications. https://doi.org/10.4135/9781446280072

Bernard, H. R., \& Ryan, G. W. (2010). Analyzing Qualitative Data. Systematic Approaches. Washington, DC: Sage

Bossuyt/CECOD. (2008). Mind the Gap: Addressing the "delivery Challenge" in EC Development Cooperation. Paper presented at the CECOD Conference on European Development Cooperation, Madrid, 27-28 November, 2008.

Callejo, M. B. (2006). Implementation gap and practices of street-level bureaucrats: the case of reception migrant students in Rotterdam. Paper presented at the conference on the Interpretative Practitioner, Birmingham, June 8-10, 2006.

Cara, O., Litster, J., Swain, J., \& Vorhaus, J. (2008). The Teacher Study: The impact of the Skills for Life strategy on teachers NRDC, Crown copyright

Cloke, P. (Ed.) (1987). Rural Planning: Policy into Action, London, UK: Harper and Row.

Coffield, F., Edward, S., Finlay, I., Hodgson, A., Spours, K., Steer, R., \& Gregson, M. (2007). How policy impacts on practice and how practice does not impact on policy.

Cohen, L., \& Manion, L., \& Morrison, K. (2000). Research Methods in Education. London, UK: Routledge.

Compass, 2005-2007 Blackwell Publishing. Accessed online at www.blackwell-compass.com on $25 / 03 / 2010$.

Cousin, G., Deepwell, F., Land, R., \& Ponti, M. (2004). Theorising Implementation: Variation and Commonality In European Approaches To E-Learning. Proceedings Network Learning Conference, Symposium 5.

Fowler, Z. (2005) History of Adult Literacy campaigns. in Politically constructing adult literacy: A case study of the Skills for Life strategy for improving adult literacy in England 1997-2002, (Doctoral thesis), Institute of Education, London.

Gatenby, I., \& Williams, C. (1996). Interpreting Planning Law. In M. Tewdwr-Jones (Ed.), in British Planning Policy in Transition: Planning in the 1990s (pp 137-153). London, UK: UCL Press. 
Gilg, A., \& Kelly, M. (1996). The analysis of development control decisions: a position statement and some new insights from recent research in south-west England. Town Planning Review, 67, 203-228. https://doi.org/10.3828/tpr.67.2.m302683w61gk1025

Gilg, A., \& Kelly, M. (1997). 'The delivery of planning policy in Great Britain: explaining the implementation gap. New evidence from a case study in rural England' Government and Policy, 15, 19 -36. https://doi.org/10.1068/c150019

Hamilton, M., \& Hillier, Y. (2006). Changing Faces of adult literacy, LANGUAGE AND NUMERACY: a critical history. Trentham Books: Stoke on trent, UK and Sterling, USA NAO (2004). Skills for Life: Improving Adult Literacy and Numeracy Skills.

Pearce, M. (1992). The effectiveness of the British land use planning system. Town Planning Review, 63, 13-28. https://doi.org/10.3828/tpr.63.1.9317w831u4t42815

Putnam, R. D. (1988). Diplomacy and domestic politics: the logic of two-level games. International Organization, 42, 427-60. https://doi.org/10.1017/S0020818300027697

Results (2010). DFID, Disability and Education: bridging the Implementation Gap. Results, UK.

Steinbach, R (2009). Problems of Policy Implementation. Public Health Action, Health Knowledge. Submission for special TLRP edition of BERJ, Revised, IOE London

Thomas, G. (2009). How to do your research project. Washington, DC: Sage.

TLRP Project: The impact of policy on learning and inclusion in the learning and skills sector Wilson, E. (2009). School-based research. Washington, DC: Sage.

Yates, S., \& Payne, M. (2007). Minding the gap' between policy visions and service implementation: lessons from Connexions. Youth and Policy, 95, 25-38. 